\title{
Methylation status of the promoter region of the human frizzled 9 gene in acute myeloid leukemia
}

\author{
YINGJIE ZHANG, QI JIANG, XIAOLIN KONG, LILI YANG, WANZHEN HU, CHENGFANG LV and YINGHUA LI \\ Department of Hematology, The First Affiliated Hospital of Harbin Medical University, \\ Harbin, Heilongjiang 150001, P.R. China
}

Received April 10, 2015; Accepted February 15, 2016

DOI: $10.3892 / \mathrm{mmr} .2016 .5387$

\begin{abstract}
The FZD9 gene is located at chromosome 7q11.23, and has been indicated to be a tumor suppressor gene. The present study examined the involvement of FZD9 promoter methylation in the downregulation of FZD9 expression in leukemia cells. The expression of the FZD9 gene was absent in various leukemic cell lines, while it was restored following treatment with DNA demethylating agent 5-aza-2'-deoxycytidine. Bisulfite sequencing analysis of the FZD9 promoter region showed that it was partially methylated in cell lines in which FZD9 gene was not expressed. Thus, DNA methylation in the promoter region may lead to inactivation of the FZD9 gene, which may represent and aberration associated with leukemia, since DNA was not methylated in normal peripheral blood mononuclear cells. Methylation-specific polymerase chain reaction analysis revealed that the promoter region of the FZD9 gene was frequently methylated in primary or relapse acute myeloid leukemia (52.9\%; excluding acute promyelocytic leukemia); however, methylation was infrequent in B-cell acute lymphocytic leukemia (5.6\%). In conclusion, the present study indicated that the methylation profile of the FZD9 gene corresponded to that of a candidate tumor-suppressor gene in acute myeloid leukemia.
\end{abstract}

\section{Introduction}

Acute myeloid leukemia (AML) is a clonal disorder arising from uncontrolled proliferation of hematopoietic progenitor or stem cells (1). Genetic and epigenetic aberrations, including promoter hypermethylation and covalent histone modification, have been implicated in the pathogenesis of leukemia (2),

Correspondence to: Professor Yinghua Li, Department of Hematology, The First Affiliated Hospital of Harbin Medical University, 23 Youzheng Street Nangang, Harbin, Heilongjiang 150001, P.R. China

E-mail: liyinghua1965@aliyun.com

Key words: FZD9, acute myeloid leukemia, DNA methylation, tumor suppressor gene leading to enhanced proliferation and self-renewal, evasion of apoptosis and differentiation arrest of leukemia stem cells.

Frizzled 9 is a of protein encoded by the FZD9 gene in humans. Members of the 'frizzled' gene family encodes seven transmembrane domain proteins that are receptors for Wnt signaling proteins. Wnt proteins secrete glycoprotein to regulate early B-cell growth and survival (3). The Wnt/FZD signaling pathway has important roles in development (4), tumorigenesis (5) and lymphoid maturation (6,7). The FZD9 gene is located within a region of chromosome 7 , which is commonly deleted in Williams Beuren syndrome (8-10). FZD9 is expressed predominantly in the muscle, kidney, bones, eyes, testis and brain, and has an important role in the maintenance of stem cell populations in the blood, skin and gut (11-14). FZD9-deficient mice show a reduction in the number of pro/pre-B cells at developmental stages (15). In addition, aberrant DNA methylation has been identified to occur during the transformation of myelodysplastic syndrome (MDS) to AML (16). In addition, non-small cell lung cancer cell lines showed a decrease of Wnt7a expression $(17,18)$, while restoration of Wnt7a and FZD9 expression inhibited cell proliferation and anchorage-independent growth, thus promoting cellular differentiation and reversing the transformed phenotype.

Aberrant Wnt signaling has been studied in a number of leukemia types, including lymphoid and myeloid lineages, as this pathway has an important role in the renewal of normal hematopoietic stem cells and its dysregulation may lead to leukemia (19). Transcriptional repression by DNA promoter hypermethylation has been shown to affect Wnt antagonists in several human malignancies, including leukemia. The loss of function of Wnt antagonists due to promoter hypermethylation contributes to the activation of the Wnt pathway in AML and may be involved in its pathogenesis, in addition to representing a possible prognostic factor $(20,21)$.

DNA methylation in the promoter region leads to epigenetic gene inactivation by transcriptional silencing (22-24). Aberrant DNA methylation of candidate tumor suppressor genes (TSGs) has been found in various tumor types and may represent an alternative pathway of TSG inactivation (25-27). The present study assessed aberrant DNA methylation of the promoter region of the FZD9 gene in hematological malignancies and examined the association between DNA methylation of the FZD9 gene and its gene expression. 


\section{Materials and methods}

Samples and DNA/RNA preparation. Total DNA was isolated from bone marrow mononuclear cells (BMMCs) (28) of 78 patients, including 51 patients with AML (excluding acute promyelocytic leukemia), 18 patients with B-cell acute lymphocytic leukemia (B-ALL), 9 patients with chronic myeloid leukemia (CML), at the time of initial diagnosis or relapse stage, who were seen at The First Affiliated Hospital of Harbin Medical University, (Nangang, China) from 2011 to 2014, and grouped according to criteria of the French-American-British classification (29). DNA was also isolated from peripheral blood mononuclear cells (PBMCs) (30) of six healthy volunteers. The patients and volunteers provided informed consent to participate in this study. In addition, 10 hematological cell lines were examined. U937, JURKAT, K562, SUP-1, THP-1, MOLT4, HL60 and NB4 cells were provided by the Blood and Lymphatic Tumor Research Center of Nagoya University (Nagoya, Japan). NALM6 and RPMI8226 were provided by the Internal Hematology Laboratory of China Medical University (Shenyang,China). Cells were maintained in RPMI 1640 culture medium (Gibco; Thermo Fisher Scientific, Inc., Waltham, MA, USA) supplemented with $10 \%$ fetal bovine serum (Thermo Fisher Scientific, Inc.) and $100 \mathrm{U} / \mathrm{ml}$ penicillin/streptomycin, and were incubated in a $5 \% \mathrm{CO}_{2}$-humidified incubator at $37^{\circ} \mathrm{C}$. Total RNA was extracted using the Aqua-SPIN RNA Isolation Mini kit (Watson, Shanghai, China) according to the manufacturer's instructions.

Reverse transcription-polymerase chain reaction (RT-PCR). First-strand cDNA was synthesized from $1 \mu \mathrm{g}$ total RNA using random hexamers as primers and Moloney murine leukemia virus-H-reverse transcriptase (Gibco; Thermo Fisher Scientific, Inc.). PCR was then performed using first-strand cDNA as a template. The PCR thermocycling program was as follows: Initial denaturation for $5 \mathrm{~min}$ at $95^{\circ} \mathrm{C}$, followed by 35 cycles of denaturation for $30 \mathrm{sec}$ at $95^{\circ} \mathrm{C}$, annealing for $30 \mathrm{sec}$ at $56^{\circ} \mathrm{C}$ and extension for $30 \mathrm{sec}$ at $72^{\circ} \mathrm{C}$, followed by a final extension for $10 \mathrm{~min}$ at $72^{\circ} \mathrm{C}$. The primers FZD9 forward (5'-TCAAGG TCAGGCAAGTGAGCA-3') and FZD9 reverse (5'-AGCTTC CAGAGGAACGCAACA-3') were used to generate 249-bp products. The PCR products were separated on $2 \%$ agarose gels and visualized by ethidium bromide staining (Shanghai Tuo Yang Biotechnology Co., Ltd., Shanghai, China). As the control, GAPDH cDNA was amplified by RT-PCR ( 25 cycles) in separate tubes by using the primers GAPDH1 (5'-CCATGG AGAAGGCTGGGG-3') and GAPDH2 (5'-CAAAGTTGT CATGGATGACC-3') to generate 225 -bp products.

Culture with 5-aza-2-deoxycytidine. On day two after seeding, U937 and K562 cells $\left(2 \times 10^{5} / \mathrm{ml}\right)$ were incubated with 5-aza-2'-deoxycytidine $(0,5$ or $10 \mu \mathrm{M}$; Sigma-Aldrich, St. Louis, MO, USA) for $24 \mathrm{~h}$. The cells were then washed with phosphate-buffered saline and incubated for another $72 \mathrm{~h}$. Finally, the cells were harvested on day five to assess mRNA expression and DNA methylation of the FZD9 gene.

Bisulfite sequencing. A total of $200 \mathrm{ng}$ genomic DNA extract from PBMCs of healthy volunteers, cell lines and clinical samples were modified by sodium bisulfite using a
DNA modification kit (Methylamp ${ }^{\mathrm{TM}}$ DNA Modification kit; Epigentek, NewYork, NY, USA). Modified DNA (25 ng) was amplified by PCR using the primers FZD9 forward (5'-GTT TTTTTTTTAGAGTAAAATGAGG-3') and FZD9 reverse (5'-ACCRAAACTACCAACCCC-3') to obtain the promoter sequence of the FZD9 gene. The methylation status of the FZD9 gene was assessed at 501-246 bp upstream of the transcription initiation site. PCR products were separated on $1.5 \%$ low-melting agarose gels, excised and then digested with $\beta$-agarase (New England Biolabs, Beverly, MA, USA). The digestion products were sub-cloned into the pMD18-T vector as previously described (31), and a minimum of 8 clones from each product were subjected to cycle sequencing (Applied Biosystems, Thermo Fisher Scientific, Inc., Waltham, MA, USA) and analyzed using the ABI 310 sequencer (Applied Biosystems).

Methylation-specific PCR (MSP). The modified DNA was selectively amplified by PCR with the primers FZD9 forward and FZD9 reverse under the conditions described above, followed by MSP analysis with the use of primer sets specific for unmethylated (U) DNA (MSP-U forward, 5'-GATTTAGTT TGAGAGTGTGGGTATG-3' and reverse, 5'-CAAAACTCC AAAAAAACACA-3') and methylated (M) DNA (MSP-M forward, 5'-ATTTAGTTTGAGAGTGTGGGTACG-3' and reverse, 5'-GAAACTCCGAAAAAACACGC-3'). The thermocycling conditions were as follows: Initial denaturation for $5 \mathrm{~min}$ at $95^{\circ} \mathrm{C}$, followed by 35 cycles of denaturation for $30 \mathrm{sec}$ at $95^{\circ} \mathrm{C}$, annealing for $30 \mathrm{sec}$ at $58^{\circ} \mathrm{C} / 62^{\circ} \mathrm{C}$ and extension for $40 \mathrm{sec}$ at $72^{\circ} \mathrm{C}$, followed by a final extension for $10 \mathrm{~min}$ at $72^{\circ} \mathrm{C}$. Each PCR was 'hot-started' at $95^{\circ} \mathrm{C}$, and the products were separated on $2 \%$ agarose gels and then visualized by ethidium bromide staining as described above.

Statistics and analysis. Each experiment was repeated 3 times. $\mathrm{X}$-test, one-way analysis of variance and logistic analysis were conducted using the SPSS software, version 16.0 (SPSS, Inc., Chicago, IL, USA). $\mathrm{P}=0.05$ was set as the test standard and $\mathrm{P}<0.05$ was considered to indicate a statistically significant difference.

\section{Results}

FZD9 expression is lost in a proportion of leukemia cell lines. The expression of the FZD9 gene in 10 leukemic cell lines and 6 normal PBMC samples was evaluated by RT-PCR. The results showed that the FZD9 gene was not expressed in six of the cell lines (U937, K562, SUP-1, THP-1, NB4 and RPMI8226) (Fig. 1). Although these cell lines were derived from diverse hematological malignancies, the loss of FZD9 gene expression tended to be more frequent in myeloid leukemia cell lines. However, the FZD9 gene was expressed in all normal PBMNC samples.

FZD9 gene expression in leukemia cells is restored by 5-aza-2'-deoxycytidine. The mechanism of the observed downregulation of the expression of the FZD9 gene was examined. The U937 and K562 cell lines, which did not express FZD9, were exposed to 5-aza-2'-deoxycytidine $(0,5$ or $10 \mu \mathrm{M})$. The results showed that the expression of the FZD9 
A

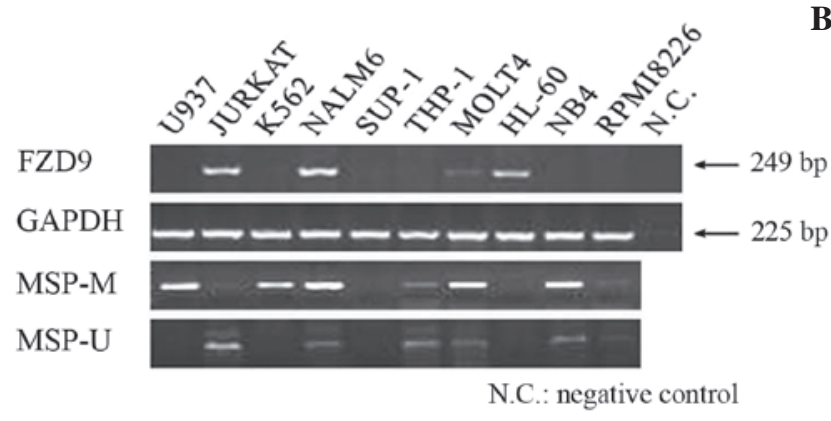

FZD9

GAPDH

MSP-M

MSP-U

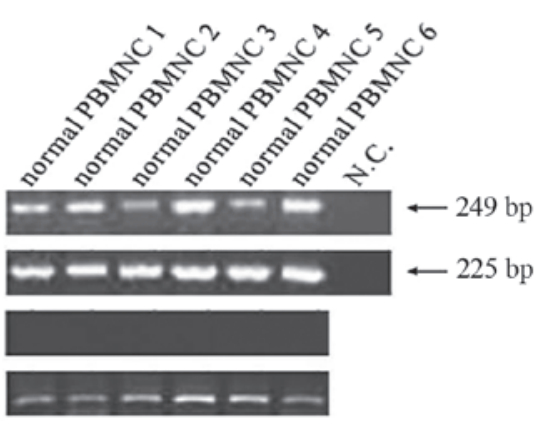

N.C.: negative control

Figure 1. Reverse-transcription PCR analysis of FZD9 gene expression and MSP analysis of FZD9 gene promoter region in (A) various cell lines and (B) normal PBMNC. PCR, polymerase chain reaction; MSP, methylation-specific PCR; MSP-M/U, MSP using primer specific for methylated/unmethylated DNA; N.C., negative control; PBMNC, peripheral blood mononuclear cells.

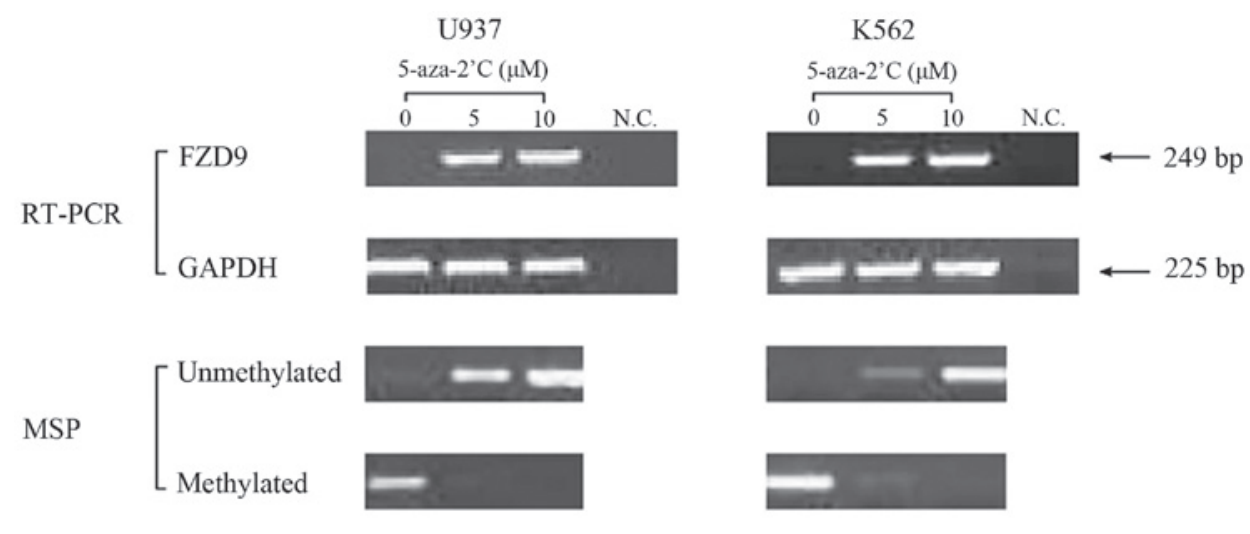

N.C.: negative control

Figure 2. Restoration of FZD9 gene expression and demethylation by 5-aza-2'-deoxycytidine in U937 and K562 cell lines as indicated by RT-PCR and MSP. RT-PCR, reverse-transcription polymerase chain reaction; MSP, methylation-specific PCR; 5-aza-2'C, 5-aza-2'-deoxycytidine; N.C., negative control.

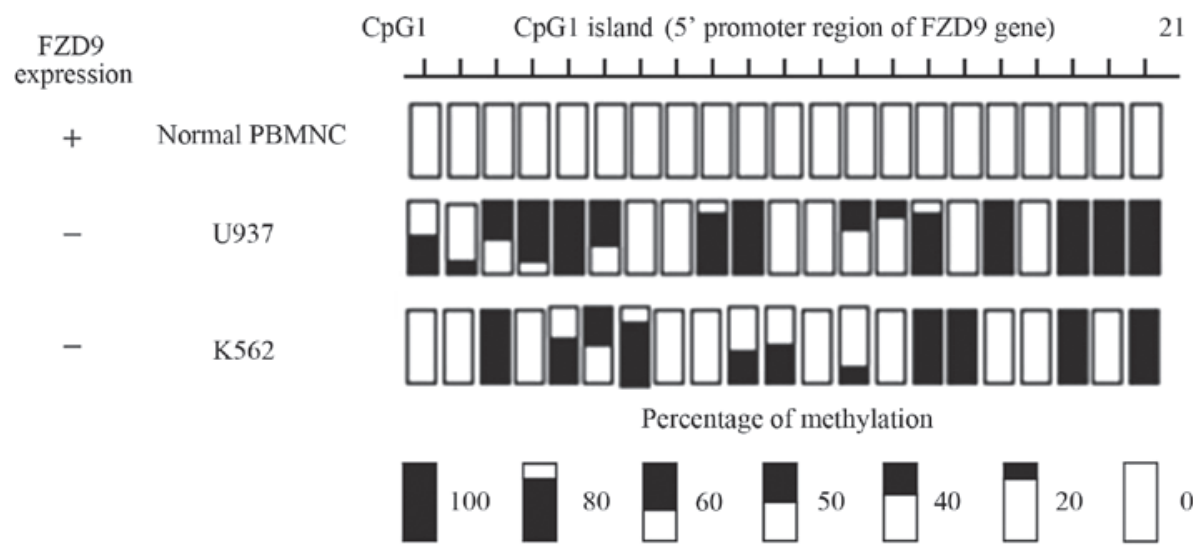

Figure 3. Methylation of the promoter region of the FZD9 gene in CpG islands and in one normal PBMNC sample, as well as in two cell lines determined by sequencing after bisulfite modification of genomic DNA. CpG 1 to 21 correspond to what is depicted in Fig. 1. Expression of the FZD9 gene was detected by reverse-transcription polymerase chain reaction, and the percentage of methylation was determined from ratios of methylated cytosine in 8 to 10 sequenced clones. White represents the amount of unmethylated and black represents methylated regions. PBMNC, peripheral blood mononuclear cells.

gene was restored in these cells following treatment with 5-aza-2'-deoxycytidine (Fig. 2).

The FZD9 gene promoter region is partially methylated in leukemia cell lines with loss of FZD9 expression. The association between DNA methylation and FZD9 gene expression was further examined by bisulfite genomic sequencing of $21 \mathrm{CpG}$ sites at the promoter region of the FZD9 gene. PBMCs from a healthy volunteer and the U937 and K562 cell lines, which did not express the FZD9 gene, were analyzed (Fig. 1). The normal PBMCs expressed the FZD9 gene and the $21 \mathrm{CpG}$ sites of the promoter region were completely unmethylated. By contrast, 
Table I. Frequency of FZD9 gene methylation in various hematological malignancies.

\begin{tabular}{lcc}
\hline Malignancy & Methylation rate of FZD9 gene & Frequency $(\%)$ \\
\hline AML (except M3) & $27 / 51$ & 52.9 \\
AML-M1 & $2 / 6$ & 33.3 \\
AML-M2 & $13 / 22$ & 59.0 \\
AML-M2 (ETO positive) & $5 / 6$ & 83.3 \\
AML-M4 & $2 / 5$ & 40.0 \\
AML-M5 & $5 / 10$ & 50.0 \\
AML-M6 & $0 / 2$ & 0.0 \\
CML & $3 / 9$ & 33.3 \\
B-ALL & $1 / 18$ & 5.6 \\
\hline
\end{tabular}

AML, acute myeloid leukemia; CML, chronic myeloid leukemia; B-ALL, B-cell acute lymphocytic leukemia.

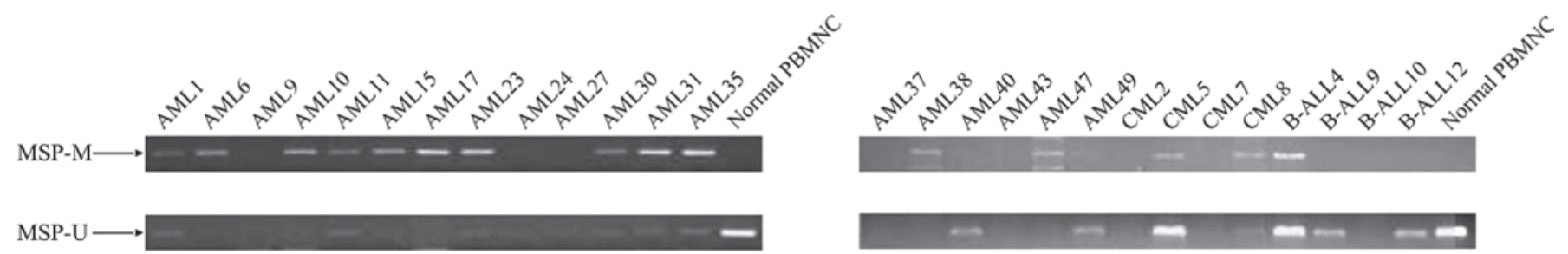

Figure 4. Analysis of FZD9 gene methylation in AML and other hematological malignancies using MSP. MSP, methylation-specific polymerase chain reaction; MSP-M/U, MSP using primer specific for methylated/unmethylated DNA; PBMNC, peripheral blood mononuclear cells.

the U937 and K562 cell lines did not express the FZD9 gene and their promoter regions were partially methylated (Fig. 3).

Methylation of FZD9 gene promoter region detected by MSP. The DNA methylation in the promoter region of the FZD9 gene was further screened using the MSP method. FZD9 gene expression in 10 leukemic cell lines was examined using MSP analysis. In analogy with the results of the bisulfite sequencing analysis, MSP analysis revealed that the DNA in the promoter regions of the FZD9 gene was methylated in the U937 and K562 cell lines. Furthermore, the NALM6, MOLT4, THP-1, NB4 and RPMI8226 cell lines showed partial methylation in their FZD9 promoter regions. However, the FZD9 promoter region of Jurkat cells was not methylated, while neither methylation nor unmethylation was detected in SUP-1 and HL-60 cell lines. In addition, analysis of the normal PBMNCs by MSP did not show any methylated bands (Fig. 1B). Analysis of patient samples showed that the methylation rate of the FZD9 gene promoter was 52.9, 33.3 and 5.6\% in AML samples, CML samples and ALL samples, respectively (Fig. 4). The frequencies of FZD9 gene methylation in various hematological malignancies are shown in Table I. These data suggested that aberrant DNA methylation of the FZD9 gene was present in certain types hematological malignancies, and that the frequency of this methylation was higher in AML compared with that in CML or B-ALL.

\section{Discussion}

In addition to point mutation or gene deletion, transcriptional repression by the hypermethylation of promoter sequences may represent an alternative mechanism of TSG inactivation in cancers (32). The FZD9 gene has been indicated to be a TSG, which has, however, remained to be directly evidenced. FZD9 expression has been shown to be decreased in chronic lymphocytic leukemia (21), myelodysplastic syndromes and non-small cell lung cancer $(17,18)$, indicating its TSG role in hematogenic malignancies.

The results of the present study suggested that the methylation status of the FZD9 gene in leukemia cell lines was reversed after treatment with the demethylating agent 5-aza-2'-deoxycytidine. While methylated bands in the K562 cell line remained after exposure to $5 \mu \mathrm{M} 5$-aza-2'-deoxycytidine, they disappeared in U937 cells, along with a restoration of FZD9 expression. These results suggested that DNA methylation of the FZD9 gene or genes that transcriptionally regulate FZD9 may represent a mechanism of the inactivation of the FZD9 gene in leukemia.

However, it is likely that silencing of FZD9 is not exclusively mediated via DNA methylation in the promoter region. Jiang et al (16) assessed the contribution of aberrant DNA methylation to TSG silencing during disease progression by DNA methylation microarray and high-density single-nucleotide polymorphism array karyotyping methods, revealing that FZD9 gene methylation was common in early MDS, and that the methylation ratio increased with the progression of the disease. Thus, despite the absence of genetic mutations, FZD9 is likely to be a TSG, which is silenced during the genesis and progression of cancers by epigenetic modifications.

MSP is a simple and sensitive method to detect DNA methylation and requires only small specimens containing limited amounts of DNA (33). In the present study, analysis of the SUP-1 and HL-60 cell lines showed that neither methylated 
nor unmethylated FDZ9 was present, indicating that FZD9 expression may be deactivated by mechanisms other than DNA methylation of its gene promoter region, such as deregulation of transcription upstream of the FZD9 gene, histone deacetylation or genetic mutations. Analysis of clinical specimens revealed that the promoter region of FZD9 was $52.9 \%$ methylated in BMMCs from patients with AML, 33.3\% methylated in BMMCs from patients with CML, but only $5.6 \%$ methylated in BMMCs from patients with B-ALL, suggesting that aberrant FZD9 gene methylation occurred more frequently in primary or relapse AML compared with other types of leukemia. In patients with B-ALL, FZD9 expression may be silenced through other mechanisms, such as gene mutations. FZD9 gene methylation was frequent in patients with AML, which was AML1/ETO fusion gene positive. Whether the methylation status of the FZD9 promoter in AML with translocation $(8,21)$ is indicative of chromosomal translocation, patient prognosis or drug resistance requires further study. An understanding of the association between methylation of the FZD9 gene promoter and the clinical outcome of primary or relapse AML may aid in the elucidation of the clinical significance of such epigenetic alterations. As only limited clinical data of the subjects were available, these associations could not be examined in the present study.

According to a previous study, FZD9 knockout mice showed no obvious features of Williams Beuren syndrome, but revealed that the FZD9 gene had an important role in lymphoid development and maturation (15). FZD9 knockout mice showed thymic atrophy, pronounced splenomegaly and lymphadenopathy with accumulation of plasma cells in lymph nodes. These results showed that the FZD9 gene was associated with abnormal B-cell development. However, the underlying mechanisms of neoplastic transformations in humans may differ from those in mice.

In conclusion, the present study indicated that the methylation profile of the FZD9 gene corresponded to that of a candidate tumor-suppressor gene in AML, and that demethylation of FZD9 may represent a novel therapeutic strategy.

\section{Acknowledgements}

This work was funded by the Specialized Research Fund for the Doctoral Program of Higher Education (no. 20132307110022).

\section{References}

1. Löwenberg B, Downing JR and Burnett A: Acute myeloid leukemia. N Engl J Med 341: 1051-1062, 1999.

2. Jones PA and Baylin SB: The fundamental role of epigenetic events in cancer. Nat Rev Genet 3: 415-428, 2002.

3. Kaucká M, Plevová K, Pavlová S, Janovská P, Mishra A, Verner J, Procházková J, Krejcí P, Kotasková J, Ovesná P, et al: The planar cell polarity pathway drives pathogenesis of chronic lymphocytic leukemia by the regulation of B-lymphocyte migration. Cancer Res 73: 1491-1501, 2013.

4. Huelsken J, Vogel R, Brinkmann V,Erdmann B, Birchmeier C and Birchmeier W: Requirement for beta-catenin in anterior-posterior axis formation in mice. J Cell Biol 148: 567-578, 2000.

5. Giles RH, van Es JH and Clevers H: Caught up in a Wnt storm: Wnt signaling in cancer. Biochim Biophys Acta 1653: 1-24, 2003

6. Yu S, Zhou X, Steinke FC, Liu C, Chen SC, Zagorodna O, Jing X, Yokota Y, Meyerholz DK, Mullighan CG, et al: The TCF-1 and LEF-1 transcription factors have cooperative and opposing roles in $\mathrm{T}$ cell development and malignancy. Immunity 37: 813-826, 2012.
7. Xu Y, Banerjee D, Huelsken J, Birchmeier W and Sen JM: Deletion of beta-catenin impairs T cell development. Nat Immunol 4: 1177-1182, 2003.

8. Fusco C, Micale L, Augello B, Teresa Pellico M, Menghini D, Alfieri P, Cristina Digilio M, Mandriani B, Carella M, Palumbo O, et al: Smaller and larger deletions of the Williams Beuren syndrome region implicate genes involved in mild facial phenotype, epilepsy and autistic traits. Eur J Hum Genet 22: 64-70, 2014.

9. Laurito S, Branham T, Herrero G, Marsa S, Garro F and Roqué M: Detection of a Williams Beuren syndrome case by MLPA. Medicina (B Aires) 73: 47-50, 2013 (In Spanish).

10. Van Hagen JM, Eussen HJ, Van Schooten R, van Der Geest JN, Lagers-van Haselen GC, Wouters CH, De Zeeuw CI and Gille JJ: Comparing two diagnostic laboratory tests for Williams syndrome: Fluorescent in situ hybridization versus multiplex ligation-dependent probe amplification. Genet Test 11: 321-327, 2007.

11. Kolben T, Peröbner I, Fernsebner K, Lechner F, Geissler C, Ruiz-Heinrich L, Capovilla S, Jochum M and Neth P: Dissecting the impact of Frizzled receptors in Wnt/ $\beta$-catenin signaling of human mesenchymal stem cells. Biol Chem 393: 1433-1447, 2012.

12. Reya T, Duncan AW, Ailles L, Domen J, Scherer DC, Willert K, Hintz L, Nusse R and Weissman IL: A role for Wnt signalling in self-renewal of haematopoietic stem cells. Nature 423: 409-414, 2003.

13. Reya T, Morrison SJ, Clarke MF and Weissman IL: Stem cells, cancer and cancer stem cells. Nature 414: 105-111, 2001.

14. Huelsken J, Vogel R, Erdmann B, Cotsarelis G and Birchmeier W: beta-Catenin controls hair follicle morphogenesis and stem cell differentiation in the skin. Cell 105: 533-545, 2001.

15. Ranheim EA, Kwan HC, Reya T, Wang YK, Weissman IL and Francke U: Frizzled 9 knock-out mice have abnormal B-cell development. Blood 105: 2487-2494, 2005.

16. Jiang Y, Dunbar A, Gondek LP, Mohan S, Rataul M, O'Keefe C, Sekeres M, Saunthararajah Y and Maciejewski JP: Aberrant DNA methylation is a dominant mechanism in MDS progression to AML. Blood 113: 1315-1325, 2009.

17. Tennis M, Van Scoyk M, Heasley LE, Vandervest K, Weiser-Evans M, Freeman S, Keith RL, Simpson P, Nemenoff RA and Winn RA: Prostacyclin Inhibits non-small cell lung cancer growth by a frizzled 9-dependent pathway that is blocked by secreted frizzled-related protein 1. Neoplasia 12: 244-253, 2010.

18. Winn RA, Van Scoyk M,Hammond M, Rodriguez K, Crossno JT Jr, Heasley LE and Nemenoff RA: Antitumorigenic effect of Wnt 7a and Fzd 9 in non-small cell lung cancer cells is mediated through ERK-5-dependent activation of peroxisome proliferator-activated receptor gamma. J Biol Chem 281: 26943-26950, 2006.

19. Khan NI and Bendall LJ: Role of WNT signaling in normal and malignant hematopoiesis. Histol Histopathol 21: 761-774, 2006.

20. Román-Gómez J, Cordeu L, Agirre X, Jiménez-Velasco A, San José-Eneriz E, Garate L, Calasanz MJ, Heiniger A, Torres A and Prosper F: Epigenetic regulation of Wnt-signaling pathway in acute lymphoblastic leukemia. Blood 109: 3462-3469, 2007.

21. Liu TH, Raval A, Chen SS, Matkovic JJ, Byrd JC and Plass C: CpG island methylation and expression of the secreted frizzled-related protein gene family in chronic lymphocytic leukemia. Cancer Res 66: 653-658, 2006.

22. Borssén M, Palmqvist L, Karrman K, Abrahamsson J, Behrendtz M, Heldrup J, Forestier E, Roos G and Degerman S: Promoter DNA methylation pattern identifies prognostic subgroups in childhood T-cell acute lymphoblastic leukemia. PLoS One 8: e65373, 2013.

23. Zhang Y, Li Q and Chen H: DNA methylation and histone modifications of Wnt genes by genistein during colon cancer development. Carcinogenesis 34: 1756-1763, 2013.

24. Portela A, Liz J, Nogales V, Setién F, Villanueva A and Esteller M: DNA methylation determines nucleosome occupancy in the 5'-CpG islands of tumor suppressor genes. Oncogene 32: 5421-5428, 2013

25. Wodarz D, Boland CR, Goel A and Komarova NL: Methylation kinetics and $\mathrm{CpG}$-island methylator phenotyope status in colorectal cancer cell lines. Biol Direct 8: 14, 2013.

26. He W, Li X, Xu S, Ai J, Gong Y, Gregg JL, Guan R, Qiu W, Xin D, Gingrich JR, et al: Aberrant methylation and loss of CADM2 tumor suppressor expression is associated with human renal cell carcinoma tumor progression. Biochem Biophys Res Commun 435: 526-532, 2013.

27. Twelves D, Nerurkar A, Osin P, Dexter T, Ward A, Gui GP and Isacke CM: DNA promoter hypermethylation profiles in breast duct fluid. Breast Cancer Res Treat 139: 341-350, 2013. 
28. Zhang L, McHale CM, Rothman N, Li G, Ji Z, Vermeulen R, Hubbard AE, Ren X, Shen M, Rappaport SM, et al : Systems biology of human benzene exposure. Chem Biol Interact 184: 86-93, 2010.

29. Lin X, Wang Z, Wang Y and Feng W: Serum MicroRNA-370 as a potential diagnostic and prognostic biomarker for pediatric acute myeloid leukemia. Int J Clin Exp Pathol 8: 14658-14666, 2015.

30. Koon HW, Shih DQ, Hing TC, Yoo JH, Ho S, Chen X, Kelly CP, Targan SR and Pothoulakis C: Human monoclonal antibodies against Clostridium difficile toxins $\mathrm{A}$ and $\mathrm{B}$ inhibit inflammatory and histologic responses to the toxins in human colon and peripheral blood monocytes. Antimicrob Agents Chemother 57: 3214-3223, 2013.
31. Xia L, Gong Y, Zhang A, Cai S and Zeng Q: Loss of GATA5 expression due to gene promoter methylation induces growth and colony formation of hepatocellular carcinoma cells. Oncol Lett 11: 861-869, 2016.

32. Li Y, Nagai H, Ohno T, Yuge M, Hatano S, Ito E, Mori N, Saito H and Kinoshita T: Aberrant DNA methylation of p57(KIP2) gene in the promoter region in lymphoid malignancies of B-cell phenotype. Blood 100: 2572-2577, 2002.

33. Uchida T, Kinoshita T, Ohno T, Ohashi H, Nagai H and Saito H: Hypermethylation of p16INK4A gene promoter during the progression of plasma cell dyscrasia. Leukemia 15: 157-165, 2001. 